\title{
The Use of Metadiscursive Markers in Letters of Recommendation: An Investigation of Gender Variations
}

\author{
Hmoud S. Alotaibi \\ Department of English Language, \\ College of Sciences and Humanities in Dawadmi, \\ Shaqra University, Saudi Arabia \\ Email: halrwais@su.edu.sa
}

Received: 4/5/2021

Accepted: 5/28/2021 Published: 6/24/2021

\section{Abstract}

This study aimed to investigate gender variations in letters of recommendation. It used the metadiscourse theory with respect to the following resources: hedges, boosters, attitude markers, engagement markers, and self-mentions. The findings showed that hedges devices were the least frequent in both groups, but at the same time were used more by males compared to female recommenders. Boosters, on the other hand, were highly frequent in both corpora and, like hedges, were employed more frequently in the male group. Interestingly, while both gender groups shared using specific hedging and boosting tokens, each gender group appeared to favor using certain devices. The attitude markers were the most frequent in the two samples and appeared more in the female group. Similarly, while both groups used specific attitude markers, each gender group seemed to use specific attitude markers. The engagement markers revealed the highest divergence between the two groups, as they appeared more frequently in female letters. Finally, both gender groups employed self-mentions equally, but female letters seemed to favor using the plural forms. The study closes with some pedagogical implications by highlighting how the theory of metadiscourse can be of importance for academics.

Keywords: gender variations, interactional markers, letters of recommendation, metadiscourse

Cite as Alotaibi, H. S. (2021). The Use of Metadiscursive Markers in Letters of Recommendation: An Investigation of Gender Variations. Arab World English Journal, 12 (2) 238-250. DOI: https://dx.doi.org/10.24093/awej/vol12no2.16 


\section{Introduction}

The genre of recommendation letters has attracted researchers recently. However, the role of gender in this important genre has not been studied from the perspective of metadiscourse. Previous studies such as Grote, Robiner and Haut (2001) showed the importance of evaluative features in letters of recommendation. They indicated that sometimes recommenders include or want to include certain evaluative features, but readers do not locate such parts in the letters. Hence, the present study investigates whether men and women recommend using different language expressions. Specifically, the study examines gender variations in terms of the use of interactional resources in the metadiscourse model by Hyland (2005). The study aims to focus on how academics use evaluative expressions to recommend their students, and at the same time, how they appeal to readers to accept their evaluation. The main research question is to what extent do men and women use evaluative language in their recommendation letters.

\section{Literature Review}

\section{The Metadiscourse Theory}

The theory of metadiscourse has been used as an essential analytical tool to explore a range of academic genres. It is an aspect of language that has been defined as "the commentary on a text made by its producer in the course of speaking or writing" (Hyland, 2017, p. 16). Hyland (2005) suggested a famous taxonomy of metadiscourse by providing two categories: interactive and interactional. The interactive category deals with transitions, frame markers, endophoric markers, evidentials, and code glosses. The interactional category addresses the hedges, boosters, attitude markers, engagement markers, and self-mentions. The elements in the interactive category fulfill textual aspects by helping produce a cohesive and coherent text. On the other hand, the elements in the interactional category are employed to establish interaction between writers/speakers and their readers/listeners.

It is important to note that metadiscourse is perceived as a fuzzy concept because it is difficult to establish its boundaries. Hyland's (2005) approach, which comprises the interactive and interactional categories, represents the broad view of metadiscourse. It considers every engagement with the reader and every internal or external reference to a text as metadiscursive units. On the other hand, Mauranen (1993) adopted a narrow approach by excluding any references to the reader and external texts. Ädel (2006) adopted a middle approach by including references to the reader on condition that they refer to participants in the world of discourse, not in the real world. The present study adopts the broad view of metadiscourse because it gained widespread acceptance from researchers due to its dynamic and inclusive view of the evaluative language.

Few studies used the metadiscourse theory to investigate the role of gender in academic language. Crismore, Markkanen, and Steffensen (1993) focused on argumentative texts written by male and female students in the United States and Finland. They found that male students used more elements of metadiscourse than female students. Specifically, hedges were used more by Finnish males compared to American males. In addition, hedges were used more by Finnish females than American females. Concerning the use of attitude markers, they were found more common in texts written by Finnish females and less common in texts by American males. 
Tse and Hyland (2008) investigated gender differences in book reviews in biology and philosophy. The researchers found that male reviewers used more interactional metadiscourse elements, i.e., hedges, boosters, and engagement markers, more than female reviewers. Yavari and Kashani's (2013) focused on research articles and found apparent variations in specific sections. For example, female writers used more attitude markers in the introduction, while male authors used more evidentials. In addition, female authors employed more attitude markers in the conclusion sections while their male counterparts used more hedges. More recently, Alotaibi (2018) explored gender variations in acknowledgment sections of doctoral dissertations written by EFL students. The study found that self-mentions were more evident in female texts. Certain elements were used for different purposes. For example, female students used boosters more when thanking for moral support and utilized attitude markers more when acknowledging academic assistance. Male writers used these elements alternatively.

\section{The Letters of Recommendation}

While the metadiscourse theory is used to investigate several academic genres, the scope has not been elaborated in the genre of the recommendation letter. The recommendation letter plays a vital role in academia because it tackles certain aspects about applicants that are not specified in other documents, such as transcripts. It evaluates students in terms of teamwork ability, motivation, personality, research skills, and adaptability, to name a few. Kong, Steele, and Botham (2021) cogently argued that letters of recommendation "are necessary for advancement at all levels of academics, as they are widely required for grants and applications ranging from graduate school to tenured academic positions."

The most comprehensive study on the generic structure of letters of recommendation was conducted by Maskara, Lau, and Lin (2014), who developed a six-move pattern. They are 1) Purpose of writing, 2) Context of knowing the applicant, 3) Applicant credentials, 4) Applicant personal values, 5) Applicant social competency, and 6) Closing remarks. Move 3 (Applicant credentials) includes four steps: 1) Classroom performance, 2) Research, and 3) Communication skill, 4) Work details. Also, move 6 (Closing remarks) contains three steps: 1) Strong recommendation, 2) Soliciting response, and 3) Best wishes. The researchers used this move analysis approach to explore cultural variations in recommendation letters written by Indian and British academics. The findings in Maskara et al.'s study are significant because they deepen our understanding of the move structure of recommendation letters and how they are built rhetorically.

Other studies have explored specific issues, especially from the psychological point of view. For example, Vidali (2009) investigated disability disclosure in five letters given to one student with a disability. She studied the letters intertextually by focusing on the attitudes of writers toward the student's disability. The feature of attitude is central in the metadiscourse theory, and thus the present study is motivated to apply it to reveal hidden messages in letters of recommendation.

In addition, Colarelli, Hechanova-Alampay, and Canali (2002) examined how the interests of recommenders influenced the tone and appeal of their letters more than the candidate's objective qualifications do. They found that "recommenders who had strong cooperative relationships with applicants wrote more favorable and longer letters than those 
whose relationships were less cooperative" (p. 335). In addition, they found that male recommenders gave more favorable recommendations to females more than to male applicants. The authors interpreted this last result as an example of men's avoidance of gender discrimination.

Grote et al. (2001) analyzed the disclosure of negative information in letters of recommendations. They created two survey samples, one survey was given to writers, and the other survey was given to readers. The recommenders' responses indicated that they would reveal such negative traits, while the responses from readers of letters indicated that they do not notice negative features. This conflict of results showed a discrepancy between what writers assume to be reporting and what they actually say. This discrepancy was taken as a significant concern in Nicklin's and Roch's (2009) study, and thus, they examined professionals' experiences and opinions regarding their writing of letters of recommendation. The analysis of the questionnaire items indicated that recommenders agree that letter inflation (i.e., exaggeration) is a problem and that they place more weight on letters written by someone they know.

\section{Exploring Gender Differences in Letters of Recommendation}

Exploring gender differences in letters of recommendation received scant attention from researchers. Bell, Cole, and Floge (1992) focused on pairs of letters written by men and women for the same male and female candidates. The study found that both genders have written differently when discussing the intellect of the applicant, as men showed more interest in discussing intellectual skills. Furthermore, men tackled candidates' publications more than women did. Trix and Psenka (2003) analyzed letters of recommendation for accepted applicants for faculty positions at an American medical school over three years. They found that the letters for female applicants were very short compared to those for males. Also, they noticed that more letters written for females had more references of "her training," "her teaching," and "her application," while letters for male applicants included more reference such as "his research," "his skills," and "his career" (p. 211). Schmader, Whitehead, and Wysocki (2007) examined how male and female applicants are recommended for faculty positions in chemistry and biochemistry at an American university. While the study did not find any significant gender differences in several aspects, the analysis showed that some letters for female applicants included more phrases related to communication. On the other hand, certain standout adjectives such as excellent, superb, outstanding, unique, and exceptional were used more significantly to describe male applicants in particular.

In another study, Nicklin and Roch (2008) examined whether gender and physical appearance influence readers' perceptions of applicants and affect selection decisions. The results were twofold. First, applicants with inflated letters were found to be more successful in being hired compared to those with non-inflated letters. Second, attractive women were more favored in non-inflated letters compared to those less attractive. These results altogether suggest that gender played no significant role in letters of recommendation.

Madera, Hebl, and Martin (2009) found that letters of recommendation for male applicants included more agentic adjectives (such as those describing independence, assertiveness, confidence, etc.). In contrast those for female applicants had more communal descriptions (e.g., kind, sympathetic, helpful). The researcher further examined whether the use 
of both types of descriptions (i.e., agentic and communal) affect hiring decisions in academia. He found that communal descriptions were negatively related to hireability, but the agentic characteristics did not reflect any rapport with hireability.

Finally, Dutt, Pfaff, and Bernstein (2016) examined the relationship between applicant gender and two outcomes of interests, i.e., letter length and letter tone. They focused on the discipline of geoscience and found that male applicants were significantly more likely to receive excellent letters than female applicants. Yet, there were no gender differences in the part of recommenders.

\section{Methods}

A set of eighty letters of recommendation were selected for the study. Forty letters were written by men, and forty were written by women. The letters were gathered through personal communication from the academics and candidates. The letters were all written by professors from different academic departments at Saudi universities and were given to Saudi students to recommend them for graduate programs. The academics were from Saudi Arabia, Egypt, Tunisia, Sudan, India, and Pakistan. The letters were written in English.

As indicated earlier, the study used the interactional metadiscourse in Hyland's (2015) model. Therefore, the letters were examined by identifying the hedges, boosters, attitude markers, self-mentions, and engagement markers. First, the researcher coded the letters by men as M1, M2, M3, etc., and the letters by women as F1, F2, F3, etc. Then, the researcher highlighted each category of metadiscourse by using a different color. The whole analysis process was conducted manually by the researcher, and the results were reviewed by a specialist in academic writing who is familiar with the theory of metadiscourse.

It is important to note that identifying the markers was conducted with respect to the context because specific markers have different meanings and functions. For instance, in Example one, the researcher considered can as a hedging device. In Example two, however, can was considered as a verb that measures the ability; therefore, it was not counted as a hedging marker.

Example one

"I can see X as an excellent, dedicated, and conscientious scholar." [M 39]

Example two

"I am certain that he can perform his assigned academic tasks in an efficient and a very satisfactory manner." [M 15]

The following is an example of the analysis of a recommendation letter in its entirety. The metadiscursive markers are underlined and are followed by the name of its category in brackets.

Example three

"It is a great [Attitude Marker] pleasure [Attitude Marker] for me [Self-mention] to recommend Mr. X. Mr. X was one of my [Self-mention] best [Attitude Marker] students at the College of Pharmacy, XX University, who always [Booster] showed [Booster] an eagerness and interest to learn and understand the role of every [Booster] 
drug in each disease. At a personal level, Mr. X is a well-disciplined [Attitude Marker], industrious [Attitude Marker] student, with a pleasant [Attitude Marker] personality,

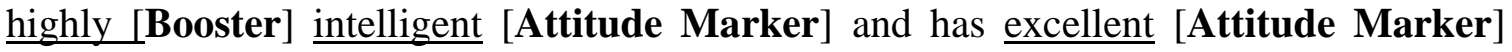
communication skills. Mr. X also demonstrated [Booster] good [Attitude Marker] team working skills in group assignments.

Mr. X's language competence is excellent [Attitude Marker] and $\underline{I}$ [Self-mention] do not expect [Attitude Marker] him to find any [Booster] difficulty from the language point of view. In my view [Attitude Marker], Mr. X compares favorably [Attitude Marker] with the best among my [Self-mention] students. I [Self-mention] feel confident [Attitude Marker] that Mr. X will continue to succeed in his career.

I [Self-mention] hope [Attitude Marker] you [Engagement Marker] will find my [Self-mention] comments helpful. If you [Engagement Marker] have any [Booster] further questions, please [Engagement Marker] feel free [Engagement Marker] to contact me [Self-mention].” [M 2].

To avoid subjectively, the analysis was reviewed by a specialist in discourse analysis who had publications on metadiscourse. Some notes were given by the specialist, especially on the analysis of attitude markers, and these were discussed and amended. Table one provides an overview of the length of letters in terms of the total number of words.

Table 1. Comparison between the two gender groups in terms of the length of letters

\begin{tabular}{llll}
\hline Written by & No. of texts & $\begin{array}{l}\text { Total no. of } \\
\text { words }\end{array}$ & $\begin{array}{l}\text { Average no. of } \\
\text { words }\end{array}$ \\
\hline Females & 40 & 6230 & 155.75 \\
\hline Males & 40 & 4892 & 122.3
\end{tabular}

\section{Results}

From Table one, it appeared that letters written by women were longer with respect to the total number of words compared to letters written by men. The analysis investigated metadiscourse markers: hedges, boosters, attitude markers, self-mentions, and engagements in the two sets of corpora. The results of each metadiscursive type will be shown in the following subsections.

\section{Hedges}

Hedges are employed by writers to reflect uncertainty and withhold commitment. Expectedly, the investigation of hedges, as shown in Table two, yielded a minimal number of instances. Male recommenders, however, have used hedging devices more than their female counterparts. As displayed in Table three, the modal can and the verb think appeared primarily on the male group (Example four), while the modal would occur only in the female group (Example five). 
Arab World English Journal (AWEJ) Volume 12. Number 2. June 2021

The Use of Metadiscursive Markers in Letters of Recommendation

Alotaibi

Table 2. The distribution of hedging devices in both gender groups

\begin{tabular}{|l|l|l|l|}
\hline & Male & Female & Total \\
\hline Hedges & 9 & 6 & 15 \\
\hline Per 1000 words & 1.9 & 1 & 1.4 \\
\hline
\end{tabular}

Table 3. The most common hedging devices in both gender groups

\begin{tabular}{|l|l|l|l|}
\hline Hedges & Male & Female & Total \\
\hline Can & 3 & 1 & 4 \\
\hline Think & 3 & 0 & 3 \\
\hline Would & 0 & 3 & 3 \\
\hline Seem & 1 & 1 & 2 \\
\hline Likely & 1 & 0 & 1 \\
\hline Expect & 1 & 0 & 1 \\
\hline Could & 0 & 1 & 1 \\
\hline
\end{tabular}

Example four

"X has a good personality and is liked by both staff and students alike. He is a flexible person and should certainly have no problems with adjustment when studying abroad. I think he will be able to complete his graduate studies successfully." [M 11]

Example five

"Her ability to ask the right questions has always helped facilitate enriching conversations about the various literary works presented in class. I would rank X in the top $10 \%$ of students I have taught the past three years in respect to her academic achievements, her eagerness to learn, as well as her diligence and hard work." [F 37]

\section{Boosters}

According to Hyland's (2005) taxonomy of metadiscourse, boosters are used to emphasize and express certainty and to indicate high confidence on the part of the writer. The analysis showed a similarity in the two groups in terms of the amount of employing booster markers, as men used 27.8 tokens per 1000 words and women used 26.2 tokens (as in Table four).

Table 4. The distribution of boosting devices in both gender groups

\begin{tabular}{|l|l|l|l|}
\hline & Male & Female & Total \\
\hline Boosters & 136 & 163 & 299 \\
\hline Per 1000 words & 27.8 & 26.2 & 26.8 \\
\hline
\end{tabular}

The examination of gender differences, as shown in Table five, shows that both gender groups shared the high frequency of using the boosters any, show, and highly. Women, however, seemed to prefer the use of the boosters: demonstrate, and always (Example six), while men seemed to favor the use of very (Example seven).

Table 5. The most common boosting devices in both gender groups

\begin{tabular}{|l|l|l|l|}
\hline Boosters & Male & Female & Total \\
\hline Any & 15 & 18 & 33 \\
\hline Demonstrate & 7 & 19 & 26 \\
\hline Show & 15 & 11 & 26 \\
\hline Highly & 12 & 13 & 25 \\
\hline Always & 4 & 17 & 21 \\
\hline
\end{tabular}


Arab World English Journal (AWEJ) Volume 12. Number 2. June 2021

The Use of Metadiscursive Markers in Letters of Recommendation

Alotaibi

\begin{tabular}{|l|l|l|l|}
\hline Very & 15 & 5 & 20 \\
\hline Strongly & 9 & 5 & 14 \\
\hline Believe & 4 & 9 & 13 \\
\hline Prove & 4 & 7 & 11 \\
\hline All & 5 & 3 & 8 \\
\hline Highest & 1 & 6 & 7 \\
\hline Truly & 0 & 5 & 5 \\
\hline Every & 4 & 0 & 4 \\
\hline
\end{tabular}

Example six

"Since she always proved to be hard worker, and cooperative, well above average who demonstrates initiative to undertake independent research." [ F 17]

Example seven

"During that period, I have had the opportunity to observe X's strong work and study habits. She is a very diligent worker, and her analytical abilities are excellent." [M 40]

\section{Attitude Markers}

Attitude markers elucidate the writer's attitude to a proposition. Specifically, they are expressions used by the speaker or writer to reveal their feelings, emotions, and views. Examining the use of attitude markers (as shown in Table six) indicates high similarity between the two gender groups, as men used 49.7 tokens per 1000 words and women employed 50.8 tokens.

Table 6. The distribution of attitude markers in both gender groups

\begin{tabular}{|l|l|l|l|}
\hline & Male & Female & Total \\
\hline Attitude Markers & 243 & 317 & 560 \\
\hline Per 1000 words & 49.7 & 50.8 & 50.3 \\
\hline
\end{tabular}

The results indicated in Table seven illustrate the most common attitude markers employed by the two gender groups. Specifically, the attitude markers: excellent, good, pleasure/pleased, hardworking were the most favored markers for women (Example eight), while men only preferred excellent and good the most (Example nine).

Table 7. The most common attitude markers in both gender groups

\begin{tabular}{|l|l|l|l|}
\hline Attitude Markers & Male & Female & Total \\
\hline Excellent & 20 & 24 & 44 \\
\hline Good & 20 & 20 & 40 \\
\hline Pleasure/pleased & 11 & 26 & 37 \\
\hline Hard-working & 12 & 20 & 32 \\
\hline Great & 9 & 12 & 21 \\
\hline Outstanding & 8 & 7 & 15 \\
\hline Wish & 6 & 8 & 14 \\
\hline Dedicated & 3 & 10 & 13 \\
\hline Impress/impressive & 6 & 5 & 11 \\
\hline Active & 3 & 7 & 10 \\
\hline Positive & 3 & 6 & 9 \\
\hline Creative & 1 & 6 & 7 \\
\hline
\end{tabular}


Example eight

"During this time, I found Ms. X to be a sincere, hardworking, and dedicated student with impressive communication skills. [F 21]

Example nine

"She is a very diligent worker, and her analytical abilities are excellent. I believe that her professionalism, maturity, and independent analytical thinking skills made her a good candidate for whatever endeavor she pursues." [M 40]

\section{Engagement Markers}

Writers use engagement expressions to address readers and build relationships with them. The analysis (as in Table eight) showed a significant divergence between the two gender groups, as female recommenders used the engagement markers (12.3 tokens per 1000 words) more than male recommenders ( 7.7 tokens). Across the two corpora, the three favorite engagement markers were you, your, and please (Example 10).

Table 8. The distribution and the most common engagement markers in both gender groups

\begin{tabular}{|l|l|l|l|}
\hline Engagement Markers & Male & Female & Total \\
\hline You & 13 & 23 & 36 \\
\hline Your & 13 & 31 & 44 \\
\hline Please & 11 & 19 & 30 \\
\hline Thank you & 0 & 2 & 2 \\
\hline Feel free & 0 & 2 & 2 \\
\hline Note & 1 & 0 & 1 \\
\hline Total & 38 & 77 & 115 \\
\hline Per 1000 words & 7.7 & 12.3 & 10.4 \\
\hline
\end{tabular}

Example 10

"If you have any questions regarding this recommendation, please do not hesitate to contact me." [F 6]

\section{Self-mentions}

The self-mentions make an explicit reference to the author. In particular, the author of the text is foregrounded through the use of first-person pronouns. The analysis of self-mentions, as indicated in Table 9, revealed that the most common tokens were I, I am, my, me (Example 11). Female writers additionally used plural cases: our and us (Example 12).

Table 9. The distribution and the most common self-mentions in both gender groups

\begin{tabular}{|l|l|l|l|}
\hline Self-mention & Male & Female & Total \\
\hline I & 104 & 110 & 214 \\
\hline I am & 17 & 25 & 42 \\
\hline My & 24 & 34 & 58 \\
\hline Me & 22 & 35 & 57 \\
\hline Our & 3 & 9 & 12 \\
\hline We & 1 & 1 & 2 \\
\hline Us & 0 & 3 & 3 \\
\hline Myself & 0 & 1 & 1 \\
\hline Mine & 1 & 0 & 1 \\
\hline Total & 172 & 218 & 390 \\
\hline Per 1000 words & 35 & 35 & 35 \\
\hline
\end{tabular}




\section{Example 11}

"It is my belief that his eagerness to succeed will serve him well in the Master's program Example 12

and I recommend him strongly." [M 8]

"X has also assisted us in our admissions office. She has successfully demonstrated leadership ability by counseling new and prospective students.” [F 28]

\section{Discussion}

The role of gender in the letter of recommendation has not been studied from the perspective of metadiscourse. To fill this research gap, the present study compared a set of forty recommendation letters written by male professors to the same number of letters written by female academics at Saudi universities. Overall, the examination of gender differences revealed more similarities than differences in both gender groups. To begin with, the genre of recommendation letters included a minimal number of hedges compared to the use of boosters. This is an unsurprising result because recommenders avoid vagueness and tentativeness; instead they stress certainty and confidence. Despite the limited use of hedges, male recommenders favored using hedges in their letters compared to female recommenders. The same result was found in the use of boosters, as while both gender groups employed similar amounts of boosters, males used them slightly more. It is important to note that while both gender groups seemed to treat hedges and boosters almost equally in their letters, they differed in their choice of the tokens. For instance, men preferred to use the hedges can and think while women preferred to use would. In addition, women favored to use demonstrate and always as boosters while very was noticeably more frequent in male letters.

It could be said that the findings concerning hedges are different from those by Trix and Psenka (2003), who discussed the use of doubt raisers, including hedges, and found that letters given to female applicants had more doubt raisers. Yet, they correlate with those by Schmader et al. (2007), who found the equal treatment of both genders in terms of the use of tentative language. It is interesting to note that the present study focused on the gender of the recommender, while Trix and Psenka (2003) and Schmader et al. (2007) focused on the gender of the applicants. This suggests that the concept of gender is subtle and thus requires careful consideration.

Concerning the employment of attitude markers in letters of recommendation, the study revealed that they were the most favorite metadiscursive items employed by recommenders. While they were approximately similar in both corpora in terms of the total number of tokens, they were slightly more frequent in the female group. Similar to the findings of hedges and boosters, men and women had similar views of using specific attitude tokens but at the same time had different preferences. For example, women opted to commence their letters with indicating their pleasure to recommend as well as describing candidates as hard-working.

This result is similar to that by Trix and Psenka (2003), who identified what they termed grindstone adjectives and found that these adjectives such as hardworking and dedicated were more common in letters given to female candidates. They argued that there was a tendency to associate effort with women and ability with men. This was also noted by Bell et al. (1992), who found that men were more likely to refer to the intellect of candidates than women do. 
Specifically, they were more willing to discuss specific intellectual abilities and skills that candidates possess.

Also, the findings in the present study correlate with those by Trix and Psenka (2003), who developed a list of standout adjectives such as excellent, unique, exceptional, and outstanding, and found that they were distributed similarly in female and male letters. These results contradict those by Schmader et al. (2007), who noticed gender variations in terms of using standout adjectives, as male candidates were described more with these adjectives. Again, these conflicting results might be due to the different research questions in each study. Yet, they indicate a critical role gender plays in the genre of the recommendation letter. More specifically, it appears that each gender group maintains different views on the construction of the letter as well as the attainment of persuasion. Thus, they convey metadiscourse meanings differently through various tokens.

Likewise, the analysis of self-mentions showed that both gender groups employed the same number of self-mentions in their letters. While both groups used the same tokens, female letters included more cases of plural forms.

Surprisingly, unlike hedges, boosters, self-mentions, and attitude markers which showed similar employment but with different usages of tokens, the investigation of engagement markers revealed a high divergence between the two gender groups, as female letters had a higher density of engagement tokens. The three engagement markers, you, your, and please appeared to be the most preferred items across the two samples of letters. The preference of using more engagement exponents in female letters reflects the female writers' tendency to include readers as discourse participants and their propensity to address readers directly. In the genre of the recommendation letter, the employment of engagement markers occurs mainly at the end when writers suggest readers contact them if further information is required. The other strategy, which was favored by male recommenders in this study, was to opt for passive forms and thus eliminate the use of second-person pronouns.

\section{Conclusion}

Due to the lack of studies that explored evaluative language in letters of recommendation, the research presented here used the theory of metadiscourse to explore gender variations. The study is the first to identify metadiscursive markers in this genre, and the results maintain metadiscourse as a practical analytical framework to demystify essential investigations such as gender variations. The study focused on the markers in the interactional category, and thus elements in the interactive category would be an area of the inquiry recommended for future research questions. In addition, the current study investigated differences concerning the gender of recommenders. Future research may further take the gender of applicants into account. The analysis of letters could also be accompanied by interviews of authors to provide further insights.

Besides its extraordinary fruitfulness of shedding light on specific investigations, the metadiscourse theory can offer pedagogical implications to academics as it includes heuristic devices for writers. Specifically, academics might be made aware of the function of certain elements. For example, some words (e.g., think, assume) are considered as hedges, and their role is to highlight the writer's reluctance and hesitation, etc. Therefore, their presence in letters of 
recommendation may result in different interpretations on the part of readers. Furthermore, the large number of tokens associated with each category in the metadiscourse theory may represent an essential and wide variety of resources for academics to choose and employ.

\section{About the author:}

Dr. Hmoud S. Alotaibi holds a Ph.D. in Applied Linguistics, and works now as head and associate professor of English at Shaqra University, Saudi Arabia. His research interests are genre analysis, academic wiring, and English for academic purposes. He published a number of research articles and a book entitled: The Structure of the Research Article in Linguistics. ORCID ID: https://orcid.org/0000-0002-7191-5844

\section{References}

Ädel, A. (2006). Metadiscourse in L1 and L2 English. Amsterdam, NL: John Benjamins. Alotaibi, H. (2018). Metadiscourse in dissertation acknowledgments: Exploration of gender differences in EFL texts. Educational Sciences: Theory \& Practice, 18,4, 899-916. http://dx.doi.org/10.12738/estp.2018.4.0247

Bell, S., Cole, C.S., \& Floge, L. (1992). Letters of recommendation in academe: Do women and men write different languages? The American Sociologist, 23, 7-22.

Bouton, L. F. (1995). A cross-cultural analysis of the structure and content of letters of reference. Studies in Second Language Acquisition, 17(2), 211-244. https://doi.org/10.1017/S0272263100014169

Colarelli, S. M., Hechanova-Alampay, R., \& Canali, K. G. (2002). Letters of recommendation: An evolutionary psychological perspective. Human Relations, 55(3), 315-344. https://doi.org/10.1177/0018726702553002

Crismore, A., Markkanen, R., \& Steffensen, M. (1993). Metadiscourse in persuasive writing: A study of texts written by American and Finnish university students. Written Communication, 10(1), 39-71.

Dutt, K., Pfaff, D., \& Bernstein, A. (2016). Gender differences in recommendation letters for postdoctoral fellowships in geoscience. Nature Geosci, 9, 805-808. https://doi.org/10.1038/ngeo2819

Grote, C. L., Robiner, W. N., \& Haut, A. (2001). Disclosure of negative information in letters of recommendation: Writers' intentions and readers' experiences. Professional Psychology: Research and Practice, 32(6), 655-661. https://doi.org/10.1037/0735-7028.32.6.655

Hyland, K. (2005). Metadiscourse: Exploring interaction in writing. London: Continuum.

Hyland, K. (2017). Metadiscourse: What is it and where is it going? Journal of Pragmatics, 113, 16-29. https://doi.org/10.1016/j.pragma.2017.03.007

Kong, JH, Steele, LJ., \& Botham, CM. (2021) Ten simple rules for writing compelling recommendation letters. PLoS Comput Biol 17(2), e1008656. https://doi.org/10.1371/journal.pcbi.1008656

Madera, J. M., Hebl, M. R., \& Martin, R. C. (2009). Gender and letters of recommendation for academia: Agentic and communal differences. Journal of Applied Psychology, 94(6), 1591-1599. https://doi.org/10.1037/a0016539

Maskara, R, Lau, K., \& Lin, C-Y. (2014). A comparative study of recommendation letters issued by Indian and British authors, Voices in Asia Journal, 2, 1-17.

Mauranen, A. (1993). Cultural differences in academic rhetoric: A textlinguistic study. Frankfurt, DE: Peter Lang. 
Nicklin, J.N., \& Roch, S.G. (2008) Biases Influencing Recommendation Letter Contents: Physical attractiveness and gender. Journal of Applied Social Psychology, 38(12), 30533074. https://doi.org/10.1111/j.1559-1816.2008.00425.x

Nicklin, J. M., \& Roch, S. G. (2009). Letters of recommendation: Controversy and consensus from expert perspectives. International Journal of Selection and Assessment, 17(1), 7691. https://doi.org/10.1111/j.1468-2389.2009.00453.x

Tse, P., \& Hyland, K. (2008). Robot Kung Fu: Gender and professional identity in biology and philosophy reviews. Journal of Pragmatics, 40(7), 1232-1248. https://doi.org/10.1016/j.pragma.2007.02.002

Schmader, T., Whitehead J., \& Wysocki, VH. (2007). A linguistic comparison of letters of recommendation for male and female chemistry and biochemistry job applicants. Sex Roles, 57(7-8), 509-14. doi: 10.1007/s11199-007-9291-4

Trix, F., \& Psenka C. (2003). Exploring the color of glass: letters of recommendation for female and male medical faculty. Discourse and Society, 14(2), 191-220.

Vidali, A. (2009). Rhetorical hiccups: Disability disclosure in letters of recommendation. Rhetoric Review, 28(2), 185-204. doi:10.1080/07350190902740042

Walters, A. M., Kyllonen, P. C., \& Plante, J. W. (2006). Developing a standardized letter of recommendation. Journal of College Admission, 191, 8-17.

Yavari, M., \& Kashani, A. F. (2013). Gender-based study of metadiscourse in research articles' rhetorical sections. International Journal of Applied Linguistics and English Literature, 2(2), 77-88. 